\title{
Time scales for scour below pipelines and around vertical piles due to nonlinear random waves
}

\author{
D. Myrhaug \\ Department of Marine Technology, Norwegian University of Science and Technology (NTNU), \\ Trondheim, Norway
}

M. C. Ong

Department of Mechanical and Structural Engineering and Materials Science, University of Stavanger, Stavanger, Norway

S. Dyrseth

Department of Marine Technology, Norwegian University of Science and Technology (NTNU), Trondheim, Norway

ABSTRACT: This paper provides a practical stochastic method by which the time scale for the equilibrium scour depth below pipelines and around slender vertical piles exposed to long-crested (2D) and short-crested (3D) nonlinear random waves can be derived. The approach is based on assuming the waves to be a stationary narrow-band random process, adopting the Forristall (2000) wave crest height distribution representing both 2D and 3D nonlinear random waves. Moreover, the time scale for regular waves given by Sumer and Fredsøe (2002) are used. Examples of results are also presented.

\section{INTRODUCTION}

The present work addresses the time scales for scour below pipelines and around vertical piles due to long-crested (2D) and short-crested (3D) nonlinear random waves. These structures, which originally were installed, e.g. on a plane bed, may experience a range of seabed conditions, i.e. the bed may be flat or rippled, and they may be surrounded by a scour hole. This is caused by the complicated threedimensional flow generated by the interaction between the incoming flow velocity, the geometry of the bed, the bed material, the ratio between the nearbed oscillatory fluid particle excursion amplitude and the diameter of the structure. Moreover, real waves are stochastic, making the problem more complex

Additional details on the general background and complexity of scour in the marine environment, as well as reviews of the problems are given in, e.g, Whitehouse (1998) and Sumer and Fredsøe (2002). These also include details of the time development of the scour depth below pipelines and around vertical piles. It is observed that a substantial amount of scour needs a certain amount of time to develop. This time $T$ is called the time scale of the scour process and is defined as (Sumer and Fredsøe, 2002)

$$
S_{t}=S\left(1-\exp \left(\frac{t}{T}\right)\right)
$$

where $S$ is the equilibrium scour depth, i.e., the scour depth corresponding to the equilibrium stage,
$S_{t}$ is the instantaneous scour depth, and $t$ is the time.

To our knowledge no studies are available in the open literature dealing with the time scales for the random wave-induced equilibrium scour depth below pipelines and around slender vertical piles.

The purpose of this study is to provide a practical stochastic method for calculating the time scales for scour below pipelines and around vertical piles due to $2 \mathrm{D}$ and $3 \mathrm{D}$ nonlinear random waves. This is achieved by using parameterized formulas for time scales for scour below pipelines and around vertical piles valid for regular waves in conjunction with a stochastic approach. Here the waves are assumed to be a stationary narrow-band random process. The effects of nonlinear waves are included by adopting the Forristall (2000) wave crest height distribution representing 2D and 3D second-order nonlinear random waves. Results are obtained for a wide range of characteristic wave steepnesses and Ursell numbers in typical real sea states. Examples of results are also provided.

\section{TIME SCALES FOR SCOUR BELOW PIPELINES AND AROUND VERTICAL PILES DUE TO REGULAR WAVES}

Following Sumer and Fredsøe (2002) the nondimensional time scale $T^{*}$ is written as

$T^{*}=\frac{\left(g(\gamma-1) d_{50}^{3}\right)^{1 / 2}}{D^{2}} T$ 
where $g$ is the acceleration due to gravity, $\gamma=\rho_{s} / \rho$ is the sediment grain density $\left(\rho_{s}\right)$ to fluid density $(\rho)$ ratio, $d_{50}$ is the median grain size diameter, and $D$ is the cylinder diameter.

The non-dimensional time scales for the equilibrium scour depth below pipelines and around slender vertical piles in regular waves are given by the following empirical formula (Sumer and Fredsøe, 2002)

$$
T^{*}=p K C^{r} \theta^{-s}
$$

where the coefficients $p, r, s$ are given as $(p, r, s)=(1 / 50,0,5 / 3)$ for pipelines and $(p, r, s)=\left(10^{-6}, 3,3\right)$ for piles; $K C$ is the Keulegan-Carpenter number defined as

$K C=\frac{U T_{w}}{D}$

Here $U$ is the undisturbed linear near-bed orbital velocity amplitude, and $T_{w}$ is the wave period. Eq. (3) is valid for live-bed scour, for which $\theta>\theta_{c r}$, where $\theta$ is the undisturbed Shields parameter defined by

$$
\theta=\frac{\tau_{w}}{\rho g(\gamma-1) d_{50}}
$$

Here $\tau_{w}$ is the maximum bottom shear stress under waves, and $\theta_{c r}$ is the critical value of motion at a flat bed, i.e., $\theta_{c r} \approx 0.05$. One should note that the scour process attains its equilibrium stage through a transition period. Thus the approach is valid when it is assumed that the storm has lasted longer than the time scale of the scour.

The maximum bottom shear stress within a wave cycle is taken as

$$
\frac{\tau_{w}}{\rho}=\frac{1}{2} f_{w} U^{2}
$$

where $f_{w}$ is the friction factor adopted from Soulsby (1997) as

$$
f_{w}=c\left(\frac{A}{z_{0}}\right)^{-d} ;(c, d)=(1.39,0.52)
$$

Here $A=U / \omega$ is the near-bed orbital displacement amplitude, $\omega=2 \pi / T_{w}$ is the angular wave frequency, and $z_{0}=d_{50} / 12$ is the bed roughness. The advantage of using this friction factor for rough turbulent flow is that it is possible to derive the stochastic approach analytically. Note that Eq. (7) is obtained as best fit to data for $10<A / z_{0}<10^{5}$.

One should notice that $K C$ can alternatively be expressed as

$$
K C=\frac{2 \pi A}{D}
$$

Moreover, $A$ is related to the linear wave amplitude $a$ by

$A=\frac{a}{\sinh k h}$

where $h$ is the water depth, and $k$ is the wave number determined from the dispersion relationship $\omega^{2}=g k \tanh k h$.

In the case of two-dimensional scour below a fixed pipeline below regular waves, Fredsøe et al. (1992) analyzed the data obtained in the work of Sumer and Fredsøe (1990) on the equilibrium scour depth $S$ below the pipeline with diameter $D$, giving the empirical formula in Eq. (3) with the given coefficients $(p, r, s)=(1 / 50,0,5 / 3)$. The tests upon which this formula is based were performed for $0.05 \leq \theta \leq 0.19$.

In the case of scour around a slender vertical pile in regular waves, Sumer et al. (1992) analyzed the data obtained in laboratory experiments, giving the empirical formula in Eq. (3) with the given coefficients $(p, r, s)=\left(10^{-6}, 3,3\right)$. The tests upon which this formula is based were performed for $0.07 \leq \theta \leq 0.19$ and $7 \leq K C \leq 34$.

More details about the scour mechanisms and the time evaluation of the scour process below pipelines and around slender vertical piles are given in Sumer and Fredsøe (2002).

\section{TIME SCALES FOR RANDOM WAVES- INDUCED SCOUR BELOW PIPELINES AND AROUND VERTICAL PILES}

\subsection{Theoretical background}

Under nonlinear waves the nonlinearity is primarily caused by the asymmetric wave velocity, i.e. that the near-bed orbital velocity is larger in the wave propagation direction than in the opposite direction. Catano-Lopera and Garcia (2007) addressed the effect of wave asymmetry on the scour depth around a finite length cylinder placed horizontally on a plane bed. In their experiments in regular waves plus currents they observed that normally the downstream length 
of the scour gap is larger than its upstream counterpart. Under waves alone this is primarily caused by the asymmetric wave velocity. Examples of wave asymmetry are shown in their Figs. $2 b$ and $3 b$. However, the effect of this asymmetry on the geometry of the scour hole was not elaborated further. In the present paper the effects of wave asymmetry are considered by using Stokes second-order wave theory.

For Stokes second-order waves the nonlinearity is primarily caused by the larger velocity under the wave crest (crest velocity) than under the wave trough (trough velocity). Based on the results by Catano-Lopera and Garcia (2007) referred to earlier, it seems that it is the largest velocity in the wave cycle (i.e. the crest velocity) which is responsible for the scour, rather than the mean of the crest velocity and the trough velocity (i.e. equal to the linear wave velocity). Thus the scour response characteristics for individual random Stokes second-order waves are obtained from Eq. (3) by replacing $U$ with $U_{m}$, i.e. the maximum near-bed orbital velocity under the wave crest. This will be elaborated upon further in the forthcoming paragraph.

At a fixed point in a sea state with stationary narrow-band random waves consistent with Stokes second-order regular waves in finite water depth $h$, the non-dimensional nonlinear crest height, $w_{c}=\eta_{c} / a_{r m s}$, and the non-dimensional nonlinear maximum horizontal particle velocity evaluated at the seabed, $\hat{U}_{m}=U_{m} / U_{r m s}$, are (Dean and Dalrymple, 1984)

$$
\begin{aligned}
& w_{c}=\hat{a}+O\left(k_{p} a_{r m s}\right) \\
& \hat{U}_{m}=\hat{a}+O\left(k_{p} a_{r m s}\right)
\end{aligned}
$$

Here $\hat{a}=a / a_{r m s}$ is the non-dimensional linear wave amplitude, where the linear wave amplitude $a$ is made dimensionless with the rms (root-meansquare) value $a_{r m s}$, and

$$
U_{r m s}=\frac{\omega_{p} a_{r m s}}{\sinh k_{p} h}
$$

Moreover, $O\left(k_{p} a_{r m s}\right)$ denotes the second-order (nonlinear) terms which are proportional to the characteristic wave steepness of the sea state, $k_{p} a_{r m s}$, where $k_{p}$ is the wave number corresponding to $\omega_{p}$ (the peak frequency of the wave spectrum) given by the dispersion relationship for linear waves (which is also valid for Stokes second-order waves) $\omega_{p}^{2}=g k_{p} \tanh k_{p} h$

Now Eq. (10) can be inverted to give $\hat{a}=w_{c}-O\left(k_{p} a_{r m s}\right)$, which substituted in Eq. (11) gives $\hat{U}_{m}=w_{c}+O\left(k_{p} a_{r m s}\right)$. Thus it appears that $\hat{a}$ can be replaced by $w_{c}$ in the linear term of $\hat{U}_{m}$, because the error involved is of second order. Consequently, by neglecting terms of $O\left(k_{p} a_{r m s}\right)$ the maximum near-bed orbital velocity under the wave crest in dimensional form can be taken as

$U_{m}=\frac{\omega_{p} \eta_{c}}{\sinh k_{p} h}$

Moreover, $A_{m}=U_{m} / \omega_{p}$ is the maximum nearbed orbital displacement under the wave crest, $\hat{A}_{m}=A_{m} / A_{r m s}$ is the non-dimensional maximum near-bed orbital displacement where

$A_{r m s}=\frac{a_{r m s}}{\sinh k_{p} h}$

Furthermore,

$\omega_{p}=\frac{U_{m}}{A_{m}}=\frac{U_{r m s}}{A_{r m s}}$

by combining Eqs. (12) and (15).

Now the Forristall (2000) parametric crest height distribution based on simulations using second-order theory is adopted. The simulations were based on the Sharma and Dean (1981) theory; this model includes both sum-frequency and differencefrequency effects. The simulations were made both for $2 \mathrm{D}$ and $3 \mathrm{D}$ random waves. A two-parameter Weibull distribution with the cumulative distribution function $(c d f)$ of the form

$P\left(w_{c}\right)=1-\exp \left[-\left(\frac{w_{c}}{\sqrt{8} \alpha}\right)^{\beta}\right] ; w_{c} \geq 0$

was fitted to the simulated wave data. The Weibull parameters $\alpha$ and $\beta$ were estimated from the fit to the simulated wave data and are based on the wave steepness $S_{1}$ and the Ursell parameter $U_{R}$ defined by

$S_{1}=\frac{2 \pi}{g} \frac{H_{s}}{T_{1}^{2}}$ 


$$
U_{R}=\frac{H_{s}}{k_{1}^{2} h^{3}}
$$

Here $H_{s}$ is the significant wave height, $T_{1}$ is the spectral mean wave period, and $k_{1}$ is the wave number corresponding to $T_{1}$. It should be noted that $H_{s}=2 \sqrt{2} a_{r m s}$ when $a$ is Rayleigh distributed. The wave steepness and the Ursell number characterize the degree of nonlinearity of the random waves in finite water depth. At zero steepness and zero Ursell number the fits were forced to match the Rayleigh distribution, i.e. $\alpha=1 / \sqrt{8} \approx 0.3536$ and $\beta=2$. Note that this is the case for both $2 \mathrm{D}$ and $3 \mathrm{D}$ linear waves. The resulting parameters for the $2 \mathrm{D}$-model are

$$
\begin{aligned}
& \alpha_{2 D}=0.3536+0.2892 S_{1}+0.1060 U_{R} \\
& \beta_{2 D}=2-2.1597 S_{1}+0.0968 U_{R}^{2}
\end{aligned}
$$

and for the 3D-model

$$
\begin{aligned}
& \alpha_{3 D}=0.3536+0.2568 S_{1}+0.0800 U_{R} \\
& \beta_{3 D}=2-1.7912 S_{1}-0.5302 U_{R}+0.284 U_{R}^{2}
\end{aligned}
$$

Forristall (2000) demonstrated that the wave setdown effects were smaller for short-crested than for long-crested waves in finite water depth, which is due to the fact that the second-order negative difference-frequency terms are smaller for $3 \mathrm{D}$ waves than for $2 \mathrm{D}$ waves. Consequently, the wave crest heights are larger for 3D waves than for 2D waves.

\subsection{Outline of stochastic method}

In a stationary narrow-band sea-state the highest among random waves are considered, as it is reasonable to assume that it is mainly the highest waves which are responsible for the scour response. It is also assumed that the sea-state has lasted long enough to develop the equilibrium scour depth. The highest waves considered here are those exceeding the probability $1 / n, w_{c 1 / n}$ (i.e. $\left.1-P\left(w_{c 1 / n}\right)=1 / n\right)$. The parameter of interest is the expected (mean) value of the time scale caused by the $(1 / n)$ th highest wave crests, which is given as:

$$
E\left[\mathrm{~T}^{*}\left(\mathrm{w}_{c}\right) \mid w_{c}>w_{c 1 / n}\right]=n \int_{w_{c 1 / n}}^{\infty} T^{*}\left(w_{c}\right) p\left(w_{c}\right) d w_{c}
$$

where $T^{*}$ is the non-dimensional time scale, and $p\left(w_{c}\right)$ is the probability density function $(p d f)$ of $w_{c}$
. More specifically, the present approach is based on the following assumptions: (1) the free surface elevation is a stationary narrow-band process with zero expectation, and (2) the time scale formula for regular waves given in the previous section (Eq. (3)), are valid for irregular waves as well. These assumptions are essentially the same as those given in e.g. Myrhaug et al. (2009), where further details are found.

For a narrow-band process $T=T_{p}$ where $T_{p}=2 \pi / \omega_{p}=2 \pi A_{r m s} / U_{r m s}$ and where Eq. (16) has been used. By taking $U=U_{m}, A=A_{m}$ and substituting this in Eq. (3) using Eqs. (4) to (8), and using from Eq. (16) that $A_{m} / A_{r m s}=U_{m} / U_{r m s}$, Eq. (3) can be re-arranged to give the time scale for individual narrow-band nonlinear random waves as (and using that $\hat{U}_{m}=w_{c}$ by neglecting terms of $\left.O\left(k_{p} a_{r m s}\right)\right)$

$$
\hat{t} \equiv \frac{T^{*}}{p K C_{r m s}^{r} \theta_{r m s}^{-s}}=w_{c}^{r-s(2-d)}
$$

where

$$
\begin{gathered}
K C_{r m s}=\frac{U_{r m s} T_{p}}{D}=\frac{2 \pi A_{r m s}}{D} \\
\theta_{r m s}=\frac{\frac{1}{2} c\left(\frac{A_{r m s}}{z_{0}}\right)^{-d} U_{r m s}^{2}}{g(\gamma-1) d_{50}}
\end{gathered}
$$

It should be noted that $K C_{r m s}$ and $\theta_{r m s}$ are uniquely defined for given values of $U_{r m s}, A_{r m s}$ and $T_{p}$.

Now the mean value of the time scale caused by the $(1 / n)$ th highest wave crests follows from Eqs. (22) and (23) as

$E\left[\hat{t}\left(w_{c}\right) \mid w_{c}>w_{c 1 / n}\right]=n \int_{w_{c l / n}}^{\infty} w_{c}^{r-s(2-d)} p\left(w_{c}\right) d w_{c}$

where $p\left(w_{c}\right)=d P\left(w_{c}\right) / d w_{c}$ with $P\left(w_{c}\right)$ as given in Eq. (17), and by using that

$w_{c 1 / n}=\sqrt{8} \alpha(\ln n)^{1 / \beta}$

The results for linear waves are obtained for $\alpha=1 / \sqrt{8}, \beta=2$. 


\section{RESULTS AND DISCUSSION}

For the time scales for random wave-induced scour below pipelines and around slender vertical piles due to $2 \mathrm{D}$ and $3 \mathrm{D}$ nonlinear waves no data currently exist in the open literature. Therefore, the results in this section should be taken as tentative, and data for comparisons are required before any conclusion can be made regarding the validity of the approach. A recent review of the authors' previous studies on random wave-induced equilibrium scour characteristics around marine structures including comparison with data from random wave-induced scour experiments is given in Myrhaug and Ong (2011a). This supports that the method should be useful as an engineering approach.

All the results presented in this section are given for $n=10$, i.e. corresponding to the mean value of the time scale for the equilibrium scour depth caused by the $(1 / 10)$ th highest wave crests. This is justified by referring to some of the authors previous studies (see e.g. Myrhaug and Ong (2011a)). They found that the scour depth and the scour width below pipelines caused by the $(1 / 10)$ th highest waves represent the upper values of the random wave-induced scour data, and thus suggesting that these values can be used for design purposes. Thus the following results will be given for $n=10$. The Forristall (2000) distribution was also applied in Myrhaug and Ong (2013) and Ong et al. (2013).

First, the main results are presented. Second, examples of results are given to demonstrate the use of the method. Finally, the appropriate Shields parameter to use is discussed.

\subsection{Main results}

A feature of interest is to compare the nonlinear results in Eq. (26) with the corresponding linear results for both $2 \mathrm{D}$ and $3 \mathrm{D}$ waves (i.e. for $\alpha=1 / \sqrt{8}, \beta=2$ ). Here $R_{1}$ denotes the nonlinear to linear ratios of the time scales for the equilibrium scour depth for pipelines and vertical piles for 2D $\left(R_{1,2 D}\right)$ and 3D $\left(R_{1,3 D}\right)$ waves. It should be noted that these ratios are both independent of $\theta_{r m s}$ and $K C_{r m s}$; only dependent on $S_{1}$ and $U_{R}$.

Another interesting feature is to compare the 3D to $2 \mathrm{D}$ results. Here $R_{2}$ denotes the ratio between the time scale for the equilibrium scour depth below pipelines (and around vertical piles) for 3D waves and the time scale for the equilibrium scour depth below pipelines (and around vertical piles) for $2 \mathrm{D}$ waves.

Figures 1 and 2 show the isocurves for the nonlinear to linear ratio for $2 \mathrm{D}\left(R_{1,2 D}\right)$ and $3 \mathrm{D}\left(R_{1,3 D}\right)$ waves plotted against wave steepness $S_{1}$ and Ursell number $U_{R}$; time scale for pipelines (Fig. 1(a) and 1(b), respectively) and vertical piles (Fig. 2(a) and 2(b), respectively). Overall, Figs. 1 and 2 exhibit the same features; both for 2D and 3D waves it appears that: for a given value of $U_{R}$, namely at a given water depth, the ratios decrease as $S_{1}$ increases; for a given value of $S_{1}$, the ratios decrease as $U_{R}$ increases (i.e. as the water depth decreases). These features appear to be physically sound since the nonlinear effects are enhanced as $U_{R}$ and $S_{1}$ increases, causing a shorter time scale giving the equilibrium scour depth. For pipelines the ratio decreases to about 0.4 for 2D waves (Fig. 1(a)) and to slightly lower than 0.4 for $3 \mathrm{D}$ waves (Fig. 1(b)). For vertical piles the ratio decreases to about 0.55 for $2 \mathrm{D}$ waves (Fig. 2(a)) and to about 0.5 for 3D waves (Fig. 2(b)). Thus it appears that the ratio is only slightly larger for $3 \mathrm{D}$ waves than for $2 \mathrm{D}$ waves. These features are also given in Figs. 1(c) (pipelines) and 2(c) (piles), which show the isocurves for the $3 \mathrm{D}$ results to $2 \mathrm{D}$ results ratio, $R_{2}$, plotted against $S_{1}$ and $U_{R}$. Overall, the results for pipelines and piles exhibit the same features; except for smaller values of $U_{R}$ (i.e. for $U_{R}$ smaller than 0.2 to 0.3 depending on $S_{1}$ ), it appears that the time scale is always longer for $2 \mathrm{D}$ waves than for 3D waves; $R_{2}$ decreases as $U_{R}$ increases (i.e. as the water depth becomes shallower). This behaviour is caused by the smaller wave setdown effects for short-crested waves than for long-crested waves as mentioned previously in Section 3.1. However, it should be noted that the difference between the results for 2D waves and 3D waves is small; $R_{2}$ decreases to about 0.9. These results are consistent with those given in Myrhaug and Ong (2011b) for long- and short-crested random wave-induced scour depth below pipelines; in their Fig. 4(a) it is demonstrated that the scour depth is larger for $3 \mathrm{D}$ waves than for 2D waves for larger values of $U_{R}$.

\subsection{Examples of results}

Examples of results are given to demonstrate the application of the method; in Section 4.2.1 and 4.2.2 for pipelines and piles, respectively. The given flow conditions for both cases are: 
Significant wave height, $H_{s}=3 \mathrm{~m}$

Water depth, $h=10 \mathrm{~m}$

$\gamma=2.65$ (as for quartz sand)

\subsubsection{Pipelines}

In this case the median grain size diameter is, $d_{50}=0.001 \mathrm{~m}$. Figure 3 shows the mean value of the nondimensional time scale for the equilibrium scour depth below pipelines caused by the (1/10)th highest wave crests, $E\left[T^{*}\right]$, versus $\theta_{r m s}$ for linear, $2 \mathrm{D}$ and $3 \mathrm{D}$ nonlinear random waves. It should be noted that these results are valid for $0.04 \leq U_{R} \leq 0.21$ and $0.05 \leq S_{1} \leq 0.13$, for which the time scale is slightly smaller for $2 \mathrm{D}$ waves than for $3 \mathrm{D}$ waves according to Fig. 1(c), and as shown in Fig. 3. Furthermore, from Fig. 3 it appears that: (1) for both linear and nonlinear waves the time scale decreases as $\theta_{r m s}$ increases (i.e. as the wave activity increases); (2) the time scale is smaller for nonlinear waves than for linear waves.

\subsubsection{Piles}

In this case the following pile diameters are given, $D=0.05 \mathrm{~m}, 0.75 \mathrm{~m}, 1.0 \mathrm{~m}$.

Now caution must be taken when applying the different parameters due to: (1) the validity range of $T^{*}$ in terms of $K C$ and $\theta$ (by replacing them with $K C_{r m s}$ and $\theta_{r m s}$ ); (2) the Ursell number, $U_{R} \leq 1$. For the given values of $H_{s}$ and $h, U_{R} \leq 1$ gives that $\quad k_{p} \geq\left(H_{s} / h^{3}\right)^{1 / 2}=0.0548$. Moreover, $K C_{r m s}=\pi H_{s} /\left(\sqrt{2} D \sinh k_{p} h\right) \quad$ which gives $K C_{r m s}=(23,15,12)$ for $D=(0.5,0.75,1.0) \mathrm{m}$. Thus the results in Fig. 4 are given for $K C_{r m s}$ up to 12.

Figure 4 shows the mean value of the nondimensional time scale for the equilibrium scour depth around slender vertical piles caused by the (1/10)th highest wave crests, $E\left[T^{*}\right]$, versus $K C_{r m s}$ for $\theta_{r m s}=0.07,0.13,0.18$ and $D=0.5 \mathrm{~m}$, $0.75 \mathrm{~m}, 1.0 \mathrm{~m}$ for linear, 2D and 3D nonlinear random waves. It should be noted that these results are valid for $0.15 \leq U_{R} \leq 1.07$ and $0.01 \leq S_{1} \leq 0.06$, for which the time scale for $3 \mathrm{D}$ waves is smaller than for 2D waves according to Fig. 2(c), and as shown in Fig. 4. Furthermore, from Fig. 4 appears for all conditions that: (1) the time scale increases as $K C_{r m s}$ increases, which is consistent with that the scour depth increases as $K C_{r m s}$ increases (Sumer and Fredsøe (2002, Fig. 3.35)); (2) the differences between the linear and nonlinear results, as well as between the results for 2D and 3D waves, increase as $K C_{r m s}$ increases. Moreover, for a given value of $K C_{r m s}$ for both linear and nonlinear waves it appears that: (3) the time scale decreases as $\theta_{r m s}$ increases (i.e. as the grain size diameter decreases); (4) the time scale decreases as the pile diameter increases (i.e. due to increased wave activity in order to obtain the same $\left.K C_{r m s}\right)$.

\subsection{Shields parameter}

For random waves it is not obvious which value of the Shields parameter to use to determine the conditions corresponding to live-bed scour. However, it seems to be consistent to use corresponding statistical values of the time scale and the Shields parameter. That is, if e.g. the value $E\left[T^{*}\left(w_{c}\right) \mid w_{c}>w_{c 1 / n}\right]$ of the time scale is considered, then the corresponding value of the Shields parameter should be used. Further details of how this value of the Shields parameter for $2 \mathrm{D}$ and 3D nonlinear random waves can be calculated are given in Myrhaug and Ong (2011b).

\section{SUMMARY AND CONCLUSIONS}

A practical stochastic approach for estimating the time scales for the equilibrium scour depth below pipelines and around slender vertical piles due to long-crested (2D) and short-crested (3D) nonlinear random waves is given.

Examples of calculation demonstrate the effects of nonlinear waves. The time scales are only slightly smaller beneath 3D nonlinear waves than beneath 2D nonlinear waves. This behaviour is attributed to the smaller wave setdown effects for 3D than for 2D waves in finite water depth.

Although simple, the present approach should be useful as a first approximation to represent the stochastic properties of the time scales for the equilibrium scour depth below pipelines and around slender vertical piles exposed to $2 \mathrm{D}$ and $3 \mathrm{D}$ nonlinear random waves. However, comparisons with data are required before a conclusion regarding the validity of this approach can be given. In the meantime the method should be useful as an engineering tool for the assessment of scour and in scour protection work. 


\section{REFERENCES}

Catano-Lopera, Y.A. \& Garcia, M.H. 2007. Geometry of scour hole around, and the influence of the angle of attack on the burial of finite length cylinders under combined flows. Ocean Eng. 34 (5, 6): 856-869.

Dean, R.G. \& Dalrymple, R.A. 1984. Water Wave Mechanics for Engineers and Scientists, Prentice-Hall, Inc., New Jersey, USA.

Forristall, G.Z. 2000. Wave crest distributions: Observations and second-order theory. J. Phys. Oceanography 30: 19311943.

Fredsøe, J., Sumer, B.M. \& Arnskov, M. 1992. Time scale for wave/current scour below pipelines. International Journal of Offshore and Polar Engineering 2 (2): 13-17.

Myrhaug, D. \& Ong, M.C. 2011a. Random Wave-Induced Scour around Marine Structures using a Stochastic Method. In: Marine Technology and Engineering, C. Guedes Soares et al. (Eds), Vol. 1,

pp. 537-562. CRC Press/Balkema,Taylor \& Francis Group, London, UK.

Myrhaug, D. \& Ong, M.C. 2011b. Long- and short-crested random wave-induced scour below pipelines. Proc. of the Institution of Civil Engineers-Maritime Engineering 164 (4): 173-184.

Myrhaug, D. \& Ong, M.C. 2013. Scour around vertical pile foundations for offshore wind turbines due to long-crested and short-crested nonlinear random waves. J. of Offshore Mechanics and Arctic Engineering, ASME 135 (1): p. 011103.

Myrhaug, D., Ong, M.C., Føien, H., Gjengedal, C. \& Leira, B.J. 2009. Scour below pipelines and around vertical piles due to second-order random waves plus a current. Ocean Eng. 36 (8): 605-616.

Ong, M.C. Myrhaug, D. \& Hesten, P. 2013. Scour around vertical piles due to long-crested and short-crested nonlinear random waves plus a currrent. Coastal Eng. 73: 106-114.

Sharma, J.N. \& Dean, R.G. 1981. Second-order directional seas and associated wave forces. Soc. of Petroleum Engineers Journal 21: 129-140.

Soulsby, R.L. 1997. Dynamics of Marine Sands. A Manual for Practical Applications, Thomas Telford, London, UK.

Sumer, B.M., Fredsøe, J. \& Christiansen, N. 1992. Scour around a vertical pile in waves. J. Waterway, Port, Coastal and Ocean Engineering 118 (1): 15-31.

Sumer, B.M. \& Fredsøe, J. 2002. The Mechanics of Scour in the Marine Environment. World Scientific, Singapore.

Sumer, B.M. \& Fredsøe, J. 1990. Scour below pipelines in waves. J. Waterway, Port, Coastal and Ocean Engineering 116 (3): 307-323.

Whitehouse, R.J.S. 1998. Scour at Marine Structures. A Manual for Practical Applications. Thomas Telford, London, UK.

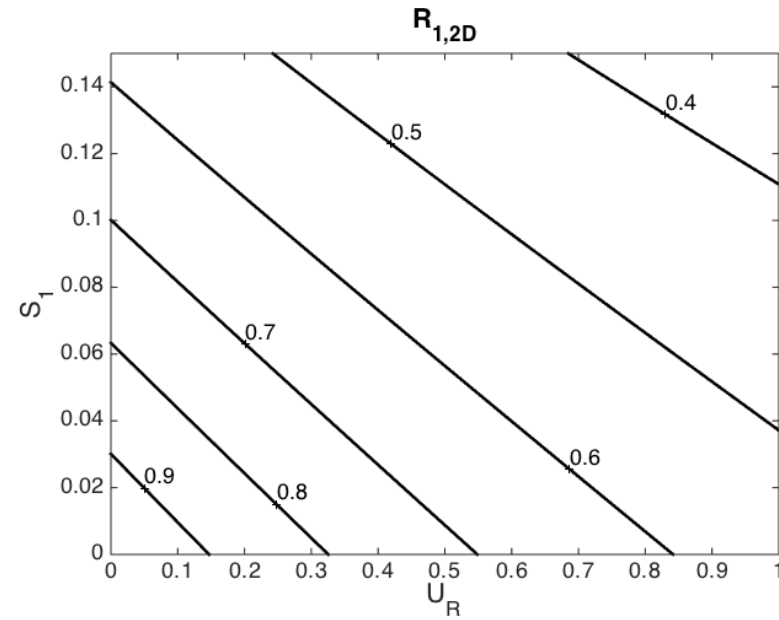

1(a)

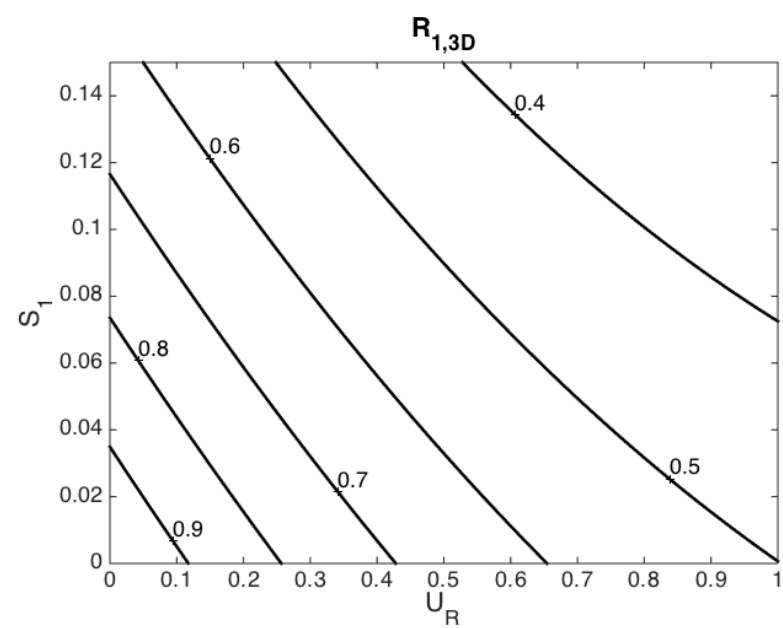

1(b)

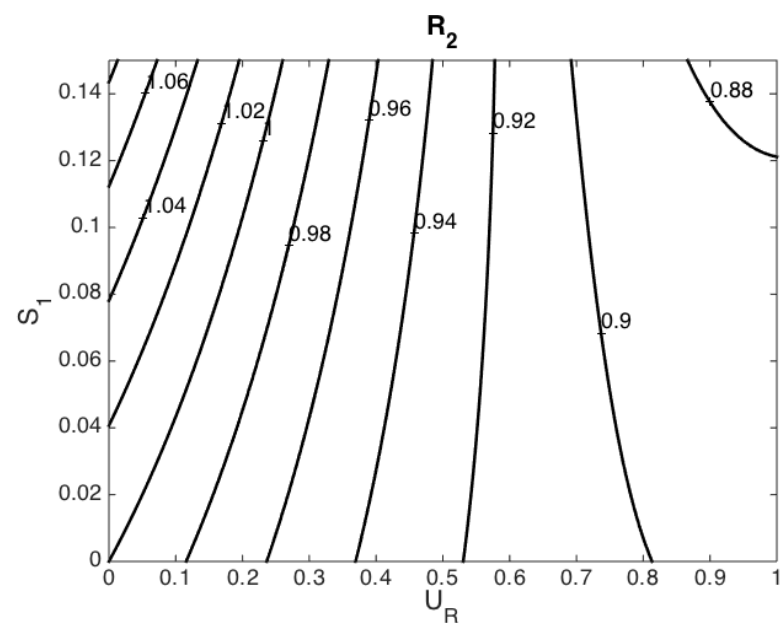

$1(\mathrm{c})$

Figure 1. Isocurves for the ratios $R_{1}$ and $R_{2}$ for the time scale for pipelines versus $U_{R}$ and $S_{1}$ for $n=10$ : (a) $R_{1,2 D}$ for $2 \mathrm{D}$ waves; (b) $R_{1,3 D}$ for $3 \mathrm{D}$ waves; (c) $R_{2}, 3 \mathrm{D}$ to $2 \mathrm{D}$ results ratio. 


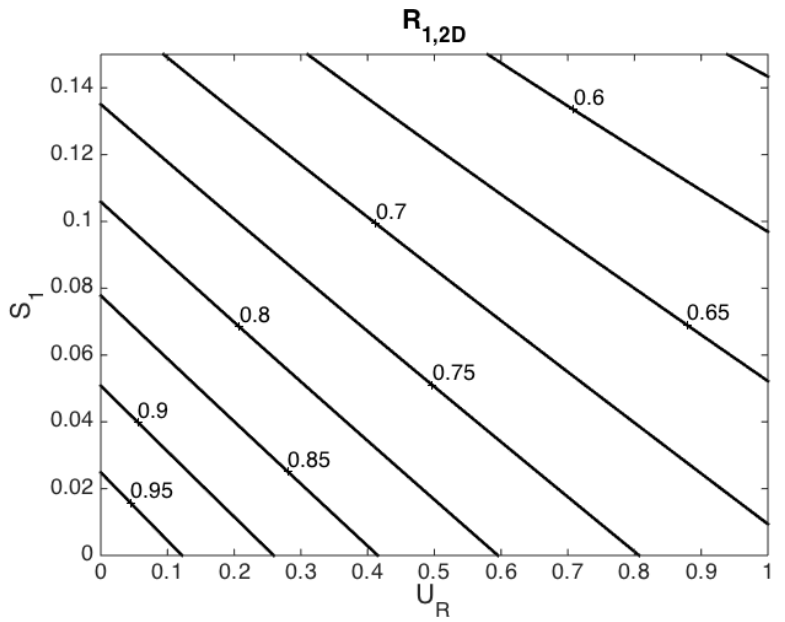

2(a)

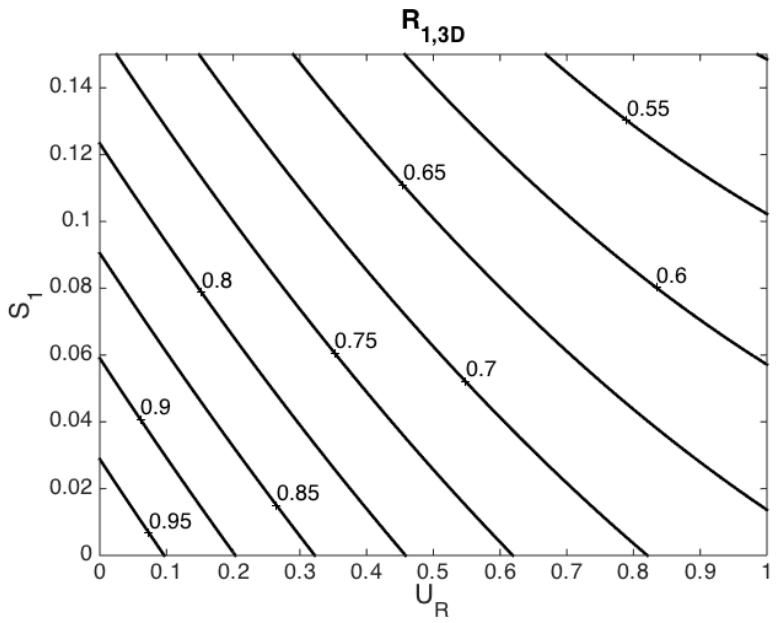

2(b)

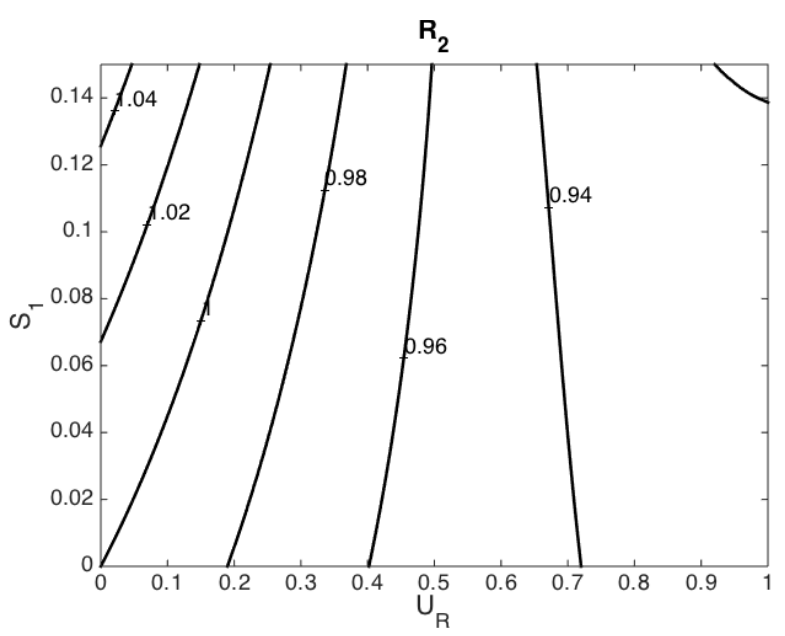

2(c)

Figure 2. Isocurves for the ratios $R_{1}$ and $R_{2}$ for the time scale for vertical piles versus $U_{R}$ and $S_{1}$ for $n=10$ : (a) $R_{1,2 D}$ for 2D waves; (b) $R_{1,3 D}$ for 3D waves; (c) $R_{2}, 3 \mathrm{D}$ to $2 \mathrm{D}$ results ratio.

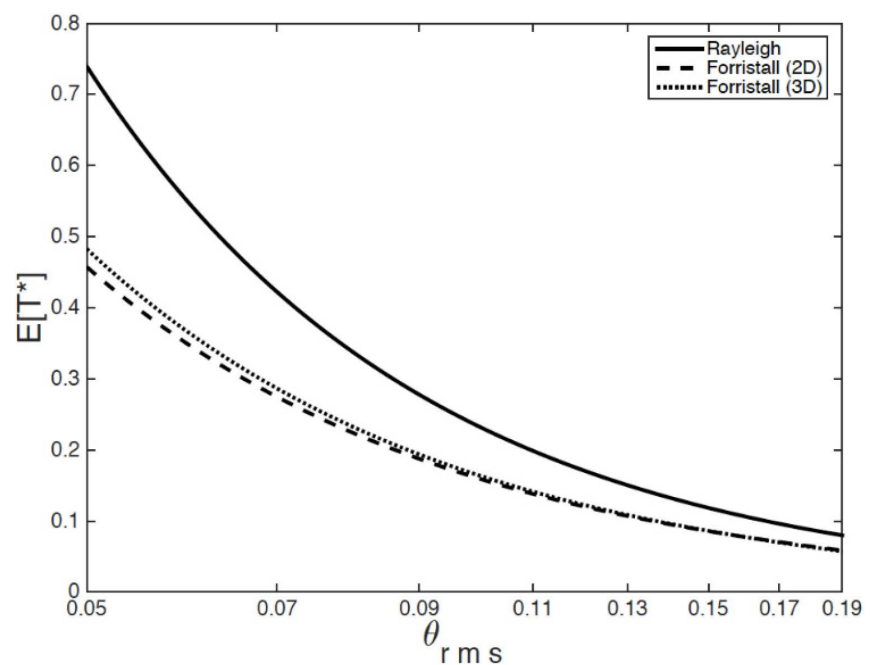

Figure 3. Expected value of non-dimensional time scale for scour below pipelines for linear, 2D and 3D nonlinear waves.

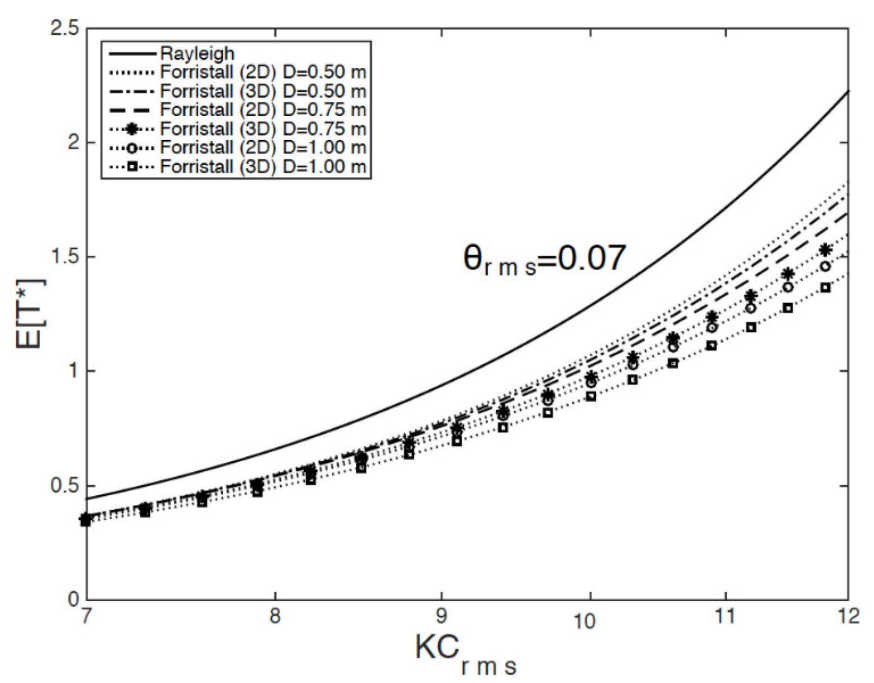

4(a)

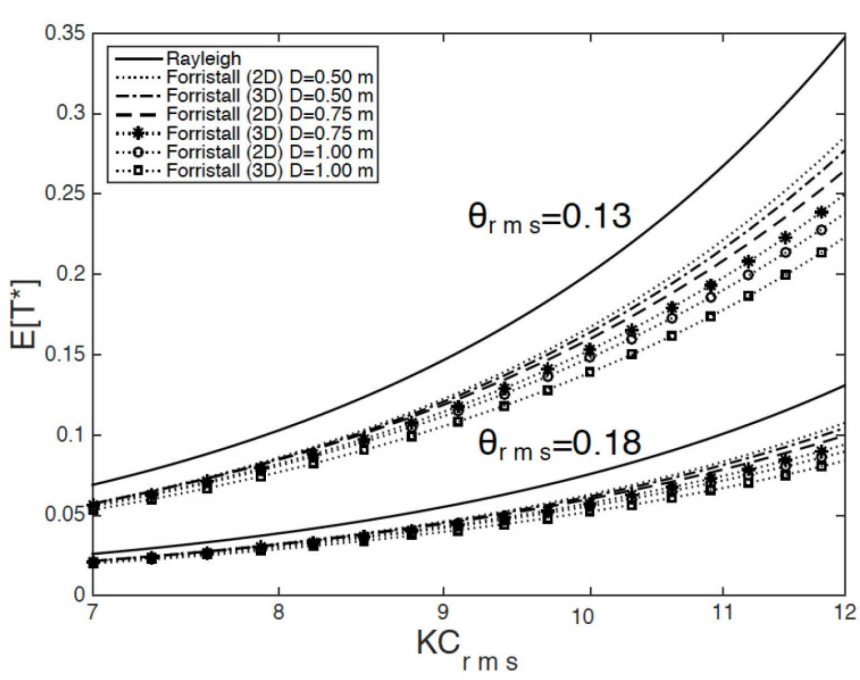

4(b)

Figure 4. Expected value of non-dimensional time scale for scour around vertical piles for linear, 2D and 3D nonlinear waves versus $K C_{r m s}$ and for $D=0.5 \mathrm{~m}, 0.75 \mathrm{~m}, 1.0 \mathrm{~m}$ : (a) $\theta_{r m s}=0.07$; (b) $\theta_{r m s}=0.13$ and 0.18 . 